\title{
О РАСПРЕДЕЛЕНИИ МИКРОЭЛЕМЕНТОВ В ПЕСТРОЦВЕТНЫХ ГЛИНИСТЫХ ПОРОДАХ ВЕНДА И КЕМБРИЯ СЕВЕРНОЙ ПРИБАЛТИКИ
}

В терригенных осадочных породах венда и кембрия Северной Прибалтики значительную часть составляют пестроцветные глинистые отложения, характеризующиеся пятнисто-полосчатым чередованием краснобурых (фиолетовых) и сероцветных, реже охристо-желтых участков. Окраска красноцветных пород обусловлена наличием в них тонкодисперсного гематитового пигмента, содержание которого во фракции $<0,001$ мм достигает 10-26\%. Это, видимо, сильно окисленный продукт размыва окружающей суши, привнесенный в виде тонкой взвеси в бассейны осадконакопления венда и кембрия. Сероцветные участки в этих глинах явно вторичны и формирование их в разнотипных бассейнах проходило по-разному. Благодаря наличию достаточного количества органического вещества в морских бассейнах кембрия и в котлинском бассейне венда пигментирующий гематит полностью восстановился и породы приобрели зеленовато-серую или серую окраску, что сопровождалось повышением относительного содержания $\mathrm{FeO}$. Так, в лонтоваских глинах соотношение $\mathrm{Fe}_{2} \mathrm{O}_{3}$ и $\mathrm{FeO}$ обычно $0,9-1,4$, в котлинских даже $0,5-0,9$, что хорошо согласуется с общей высокой редуцированностью пород этих свит, выраженной путем соответствующих коэффициентов (Пиррус, 1980).

При субконтинентальном режиме осадконакопления (гдовская и воронковская свиты венда) органического вещества было очень мало и его хватило только для очагового восстановления гематита в ходе диагенеза.* В более ощутимых масштабах процесс восстановления проходил в вендских глинах позднее - очевидно, под воздействием сильновосстановительных грунтовых растворов, фильтровавшихся в породу извне. Об этом свидетельствует развитие очагов и зон восстановления в основном по наиболее алевритовым слоям отложений или вокруг вертикальных трещин и гнезд более грубозернистого материала. В результате этих процессов в рассматриваемых свитах и образовалась характерная красно-буро-серая пестроцветность оглеения (Перельман, 1968; Борисенко, 1980) с явным преобладанием первичной красно-бурой окраски в наиболее массивных слоях глин.

Особое и, очевидно, промежуточное место по генезису занимает пестроцветность в глинистых породах трансгрессивного максимума лонговаской свиты кембрия. В условиях сравнительно глубоководных участков моря к этому времени еще не было достигнуто плотного заселения морского дна донными организмами, ввиду чего погребенной органики оказалось недостаточно для-полного восстановления окисных форм железа. Процессы редукции развивались интенсивнее вокруг более круп-

* Битюков а Л. Я. Органическое вещество в глинистых толщах венда и кембрия Северной Прибалтики. Мат. 6-й конференции молодых ученых МГУ. М., 1979 (Рукопись депонирована в ВИНИТИ 21 авг. 1979 г., № 3132-79). 
ных остатков организмов и слабее - фронтально по всей толще осадка. В результате образовалась очаговая пестроцветность в виде нечетких пятен, полос и разводов сероцветной окраски на фоне красно-бурой или еще чаще бледно-фиолетовой, затронутой фронтальной редукцией глины. В отличие от гдовской и воронковской свит в морских глинах лонтоваской свиты восстановление железа протекало явно на ранних стадиях диагенеза.

Во всех отмеченных случаях формирование полос и пятен сероцветной окраски сопровождалось не только восстановлением окислов железа, но и значительным выносом последнего из системы. Соответствующее соотношение содержания общего $\mathrm{Fe}_{2} \mathrm{O}_{3}$ в красно-бурых и сероцветных глинах наибольшее $(2,8-6,5)$ в гдовской и воронковской свитах, наименьшее в лонтоваской свите $(1,5)$. Последнее вполне понятно, если учесть замкнутость системы в условиях диагенеза в малопроницаемом глинистом осадке (лонтоваская свита) и большую открытость ее при катагенетической фильтрации растворов-восстановителей вдоль более грубозернистых прослоев пород (гдовская и воронковская свиты).

Кроме того, во всех отмеченных свитах с пестроцветной окраской пород наблюдается также окрашивание, глин охристо-желтым гетитовым пигментом, которое встречается послойно и обусловлено кратковременной внезапной аэрацией осадков на дне водоема. Очень редкие, однако весыма выдержанные в пространстве такие полосы в лонтоваской свите, более частые в гдовской и воронковской свитах, где они могут быть свидетелями даже кратковременного выхода отложений из-под зеркала воды. Эти охристо-желтые участки богаче суммарным железом, чем вмещающие сероцветные породы, что позволяет предположить при формировании их и некоторый привнос железа извне, точный механизм которого до настоящего времени окончательно не выяснен.

Естественно, что на фоне такой контрастной пестроцветности, отражающей перераспределение одного из породообразующих компонентов осадка, значительный интерес представляет поведение примесных элементов, привнесенных в изученные бассейны также преимущественно в составе тонкодисперсной глинистой взвеси.

Для изучения поведения малых элементов в процессах, приведших к формированию пестроокрашенного комплекса пород, составлены выборки образцов алевритовых глин трех основных разновидностей - красноцветных, сероцветных и охристо-желтых. Общее количество проб 230, из них сероцветные разности представлены 167 , красноцветные - 50 и охристо-желтые - 13 пробами. Содержание элементов определяли методом приближенно-количественного спектрального анализа с использованием контрольных образцов, анализировавшихся методом количественного спектрального анализа. Результаты анализов обрабатывали методами математической статистики, сравнение средних проводили с помощью критерия Стьюдента на $5 \%$-ном уровне значимости.

На основании полученных результатов построены графики средних содержаний элементов в разноокрашенных породах по свитам (рис. 1) и проведено сравнение содержаний малых элементов в однотипных породах различных свит (рис. 2).

В глинах гдовской свиты, сформировавшейся в основном за счет продуктов выветривания кристаллического фундамента, в красноцветных породах обнаружено наивысшее содержание большинства изученных элементов. Исключение составляют только $\mathrm{Zr}, \mathrm{Pb}$ и $\mathrm{Ni}$, максимумы содержания которых приурочены либо к сероцветной разности пород $(\mathrm{Zr}, \mathrm{Ni})$, либо к охристо-желтым породам $(\mathrm{Pb})$. Маконмальное содержание $\mathrm{Zr}$ в сероцветах объясняется накоплением его в основном в наиболее грубозернистых фракциях глин, которых больше по вышеупомянутым причинам именно в сероцветных разностях пород. В целом глины гдовской 

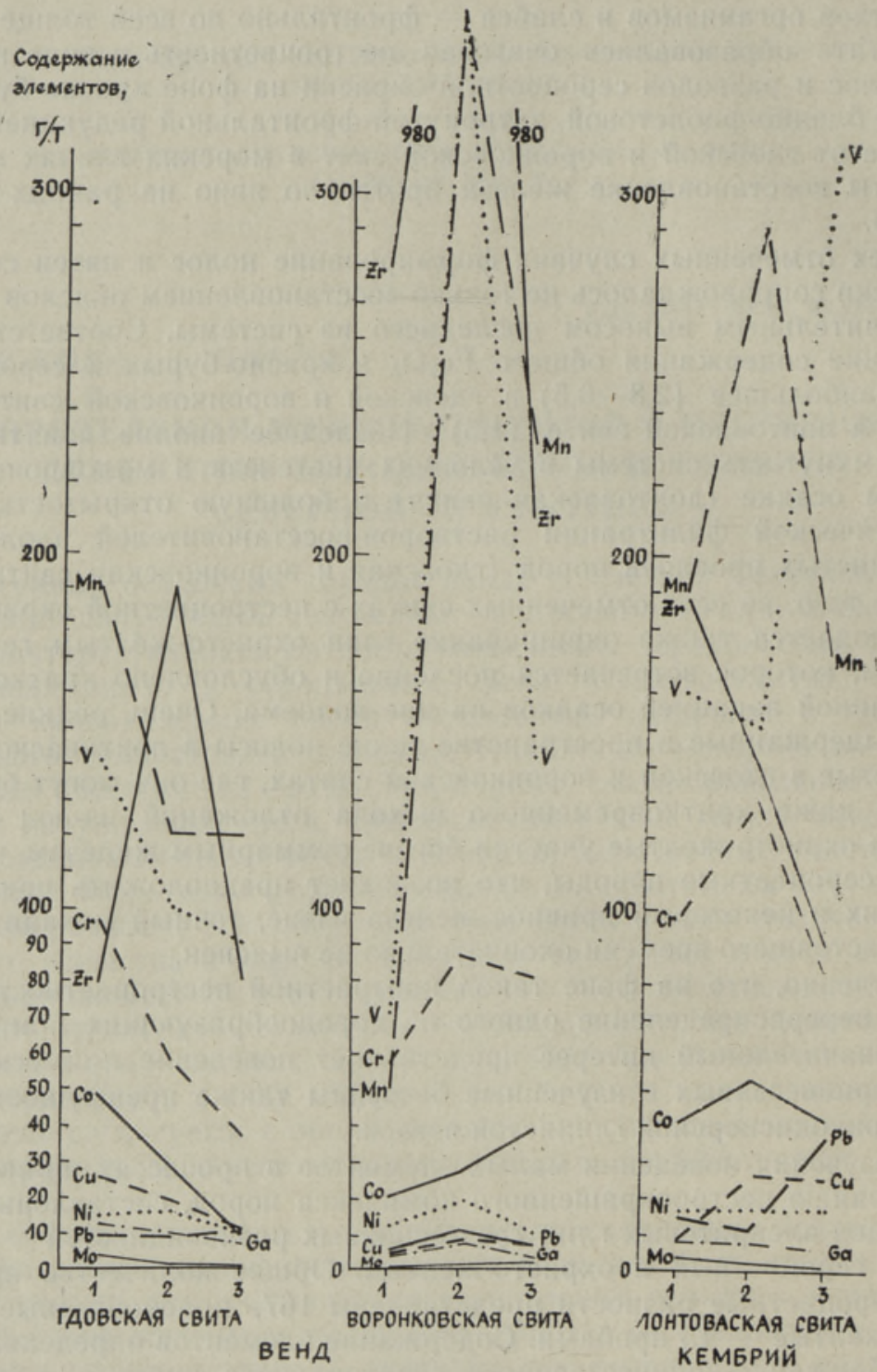

Рис. 1. Среднее содержание элементов в разноцветных разновидностях глинистых пород изученных свит. 1 - красноцветные, 2 сероцветные, 3 - охристо-желтые породы.

свиты характеризуются более высоким уровнем содержания большинства определенных микроэлементов, чем породы других свит. Эта закономерность в значительной степени может быть объяснена формированием свиты непосредственно за счет продуктов разрушения пород фундамента без выноса вещества на большие расстояния. Охристо-желтые породы гдовской свиты отличаются низким содержанием элементов по сравнению с другими разновидностями пород. В этом, возможно, проявляется разбавляюеее влияние наложенного гетитового пигмента, в котором элементы встречаются в ничтожном количестве. Не исключается также частичный вынос некоторых элементов, например, $\mathrm{V}, \mathrm{Cr}$ и $\mathrm{Co.}$

Совсем иной тип распределения наблюдается в воронковской свите, хотя гдовские и воронковские отложения весьма близки по условиям 


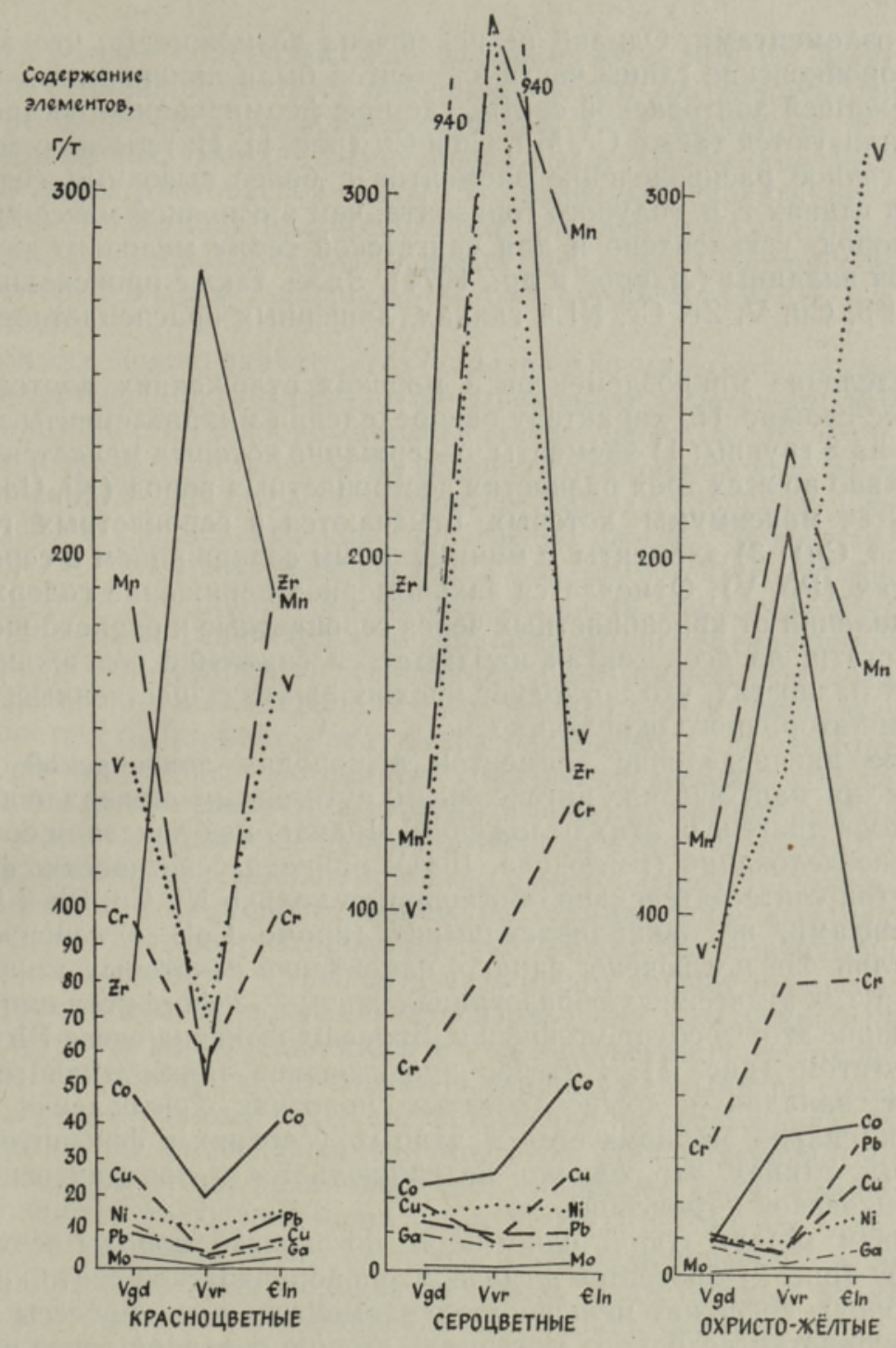

Рис. 2. Среднее содержание элементов в одинаковых цветовых разновидностях глинистых пород.

формирования. В глинах воронковской свиты максимум накопления элементов наблюдается в сероцветных разновидностях при сравнительно низком уровне их в красноцветных. Низкий уровень содержания элементов в красноцветных глинах воронковской свиты по сравнению с таковым гдовской свиты объясняется, вероятно, тем, что воронковские глины более переработанные зрелые породы, в которых связь с исходными продуктами разрушения фундамента слаба. Однако факт обогащения микроэлементами именно сероцветных пород трудно объясним. Возможно, что при восстановлении дисперсного гематита частично мобилизовались и некоторые микроэлементы, например, $\mathrm{Mn}, \mathrm{V}, \mathrm{Cr}, \mathrm{Co}, \mathrm{Ni}, \mathrm{Pb}, \mathrm{Cu}$, которые фиксировались в сероцветных глинах, где сорбционная поверхность глинистых минералов не была блокирована окислами железа. В охристо-желтых глинах содержание большинства элементов снижается в такой мере, которое объяснимо разбавлением породы гетитом, обеднен- 
ным микроэлементами. Однако не исключена возможность, что в сероцветные воронковские глины часть элементов была привнесена извне из вышележащей лонтоваской свиты, где при формировании пестроцветности мобилизуются также $\mathrm{Cr}, \mathrm{Mn}, \mathrm{Co}$ и $\mathrm{Cu}$ (рис. 1). Интересно отметить, что аналогичное распределение элементов с более высокими содержаниями их в глинах т. н. голубого горизонта, чем в основной массе красноцветных пород, установлено и для чангетской серии мелового возраста Ферганской впадины (Лавров и др., 1974). Здесь также происходило накопление $\mathrm{Pb}, \mathrm{Cu}, \mathrm{V}, \mathrm{Zr}, \mathrm{Cr}, \mathrm{Ni}$ в глинах, лишенных красноцветного пигмента.

Распределение микроэлементов в морских отложениях лонтоваской свиты более сложно. По характеру распределения микроэлементы можно разделить на 3 группы: 1) элементы, содержание которых меняется очень незначительно во всех трех разностях пестроцветных пород ( $\mathrm{Ni}, \mathrm{Ga}, \mathrm{Mo})$; 2) элементы, максимумы которых отмечаются в сероцветных глинах $(\mathrm{Mn}, \mathrm{Cr}, \mathrm{Co}, \mathrm{Cu})$; 3) элементы с минимальным содержанием в сероцветных породах $(\mathrm{Pb}, \mathrm{V})$. Отмечается закономерное понижение содержания $\mathrm{Zr}$ в направлении от красноцветных через сероцветные к охристо-желтым глинам. Кстати, во всех свитах наблюдается снижение содержания $\mathrm{Zr}$ в охристых разностях, что позволяет предположить существенный вынос его во время вторичного окнсления глин.

Сложное распределение элементов в породах лонтоваской свиты объяснимо, на наш взгляд, интенсивным аутигенным минералообразованием в ходе диагенеза этих отложений. Правда, как показали соответствующие исследования (Битюкова, 1981), раннедиагенетические формы пирита в этой свите интенсивно обогащаются только $\mathrm{Ni}, \mathrm{Co}, \mathrm{Pb}$ и $\mathrm{Mo}-$ т. е. элементами, не накапливающимися (кроме Co!) в сероцветных участках глин. Не исключено, однако, накопление некоторых микроэлементов в других аутигенных образованиях свиты - в фосфатах или глауконите. Вопрос этот требует уточнения. Более однозначна связь Рb с вторичным гетитом (рис. 1). Интерес представляет также значительное накопление ванадия в охристо-желтых полосках лонтоваскнх глин. Видимо, он сильно мобилизуется в данных условиях и фиксируется в гетитоносных глинах, что, однако, не наблюдается в породах вендских свит (воронковской и гдовской).

Сравнивая между собой однотипные по окраске породы всех изученных свит (рис. 2) бросается в глаза, что в воронковской свите красноцветные породы содержат меньше всего элементов, хотя процессы химической переработки исходного материала именно в данной свите играли наиболее существенную роль. Исключение составляет $\mathrm{Zr}$ - максимальное содержание его наблюдается именно в воронковской свите независимо от цветовой характеристики пород. Поскольку основным носителем этого элемента в виде устойчивого кластогенного минерала служит циркон, то обогащение им наиболее зрелой части разреза вполне объяснимо. В целом надо полагать, что в воронковское время микроэлементы имели возможность для наивысшей дифференциации, ввиду чего каолинитоносные глины этого уровня, сформировавшиеся частично на суше, могли содержать их в сорбированном виде лишь в небольшом количестве.

Наименьшими концентрациями микроэлементов в сероцветных породах характеризуется гдовская свита. Следовательно, вынос элементов при формировании сероцветных очагов в ней был существенным и приближался к выносу из открытой системы. Лонтоваские сероцветы наиболее богаты малыми элементами, что свидетельствует о фиксации перераспределяющихся элементов по схеме замкнутой системы. Исключение составляют (кроме $\mathrm{Zr}$ ) $\mathrm{Mn}$ и $\mathrm{V}$, максимальные концентрации которых наблюдаются в сероцветных глинах воронковской свиты. Причины их концентрирования в этих условиях не совсем ясны. 
Несколько более высокое содержание $\mathrm{V}, \mathrm{Mn}, \mathrm{Cr}$ и Co в охристожелтых глинах отмечается в воронковской и лонтоваской свитах, однако оно не достигает, как правило, уровня этих элементов в сероцветных глинах, за исключением отмеченного выше содержания ванадия в охристых глинах лонтоваской свиты. Это позволяет сделать вывод о том, что в процессе постдиагенетического обохривания глин микроэлементы практически не мобилизовались и существенно не перераспределялись. Это относится также к марганцу, частому спутнику железа в аналогичных процессах.

В итоге можно сказать, что большинство малых элементов ведет себя сравнительно индифферентно по отношению к условиям формирования пестроцветности, сопровождаемым интенсивным восстановлением и выносом железа в зонах и оч́агах возникшей сероцветности. Более заметный вынос малых элементов наблюдается только в гдовской свите, материал которой сформировался непосредственно за счет продуктов выветривания подстилающего фундамента и поэтому первоначально наиболее гетерогенен. Не исключено также, что часть элементов в этих породах сорбирована не глинистыми минералами, а пигментирующими окислами железа и они неизбежно освобождаются в процессе позднейшей редукции. В породах вышележащих свит, несмотря на их резкую фациальную контрастность, элементы ведут себя одинаково - перераспределение их не коррелируется с поведением соединений железа, и даже наоборот, элементы концентрируются нередко именно в сероцветных породах благодаря аутигенному минералообразованию в этих условиях.

Перечисленные закономерности, однако, следует считать предварительными, так как они основаны на ограниченном фактическом материале и требуют корректировки в дальнейшем. Математический контроль данных по критерию Стьюдента на $5 \%$-ном уровне значимости показал, что существенными могут считаться различия между краснощветными и сероцветными разновидностями пород в гдовской свите только по содержанию Со, между сероцветными и охристо-желтыми по содержанию Со и Мо; в воронковской свите соответственно по содержанию $\mathrm{Mo}, \mathrm{Zr}$ и $\mathrm{Ga}$, в лонтоваской по содержанию $\mathrm{Mn}$ и $\mathrm{Zr}$. При сравнении между собой красноцветных глин различных свит наиболее существенные различия наблюдаются по содержанию $\mathrm{Cr}, \mathrm{Co}, \mathrm{V}, \mathrm{Mn}, \mathrm{Pb}, \mathrm{Cu}$ и $\mathrm{Ga}$ (для гдовской и воронковской свит) и $\mathrm{V}, \mathrm{Mn}$ и $\mathrm{Cu}$ (для воронковской и лонтоваской свит). В сероцветных породах наиболее существенные различия выявляются только по содержанию Со. Для охристо-желтых пород изучаемых свит значимых различий по критерию Стьюдента в содержаниях элементов не наблюдается. Отсутствие существенных различий может быть связано с недостаточным числом проб в отдельных выборках и относительно большими вариациями содержаний элементов внутри их. Большая неравномерность распределения элементов в оглеенных породах присуша породам всех красноцветных формаций (Борисенко, 1980). Однако, отмеченные тенденции позволяют сориентировать дальнейшие исследования по изучению геохимии пестроцветов данного региона и отметить наиболее интересные аспекты.в поведении отдельных элементов в этих условиях.

\section{ЛИТЕРАТУРА}

Битюкова Л. Я. Некоторые особенности геохимии малых элементов в осадочных пиритах венда и кембрия Прибалтики. - В кн.: Аутигенные минералы терригенных отложений Прибалтики. Таллин, 1981, 91-106.

Бо р и с ен ко Е. Н. Геохимия глеевого катагенеза в породах пестроцветной формации. M., 1980.

Л а в ров В. В., Т еплова Л. С., Б а рин Ю. Н. Палеогеографическая обстановка накопления меловых красноцветов Ферганы по геохиммческим показателям. Докл. АН СССР, 1974, 214, 166-168. 
Пе р ел ь м а н А. И. Геохимия эпигенетических процессов. М., 1968.

П и р р у с Э. Некоторые особенности диагенетического железорудного процесса в глинистых толщах венда и кембрия Прибалтики. - В кн.: Геохимические показатели при изучении геологических процессов и поисках полезных нскопаемых. Минск, 1980, 68-72.

Московский государственный университет им. М. В. Ломоносова

Поступила в редакцию Ннститут геологии

Академии наук Эстонской ССР

\section{BITJUKOVA, E. PIRRUS}

\section{MIKROELEMENTIDE JAOTUSEST PÖJA-BALTIKUMI VENDI JA KAMBRIUMI KIRJUTES SAVIKIVIMITES}

On esitatud spektraalanalüüsi andmed mikroelementide jaotuse kohta vendi ja kambriumi savikivimites. Läbilõikes puudub elementide ühtne jaotusseaduspära primaarsete punaste ja sekundaarsete hallide kivimierimite vahel - eri stratigraafilistes üksustes on need seosed erinevad. Erinevused ilmnevad isegi lähedastes tingimustes kujunenud gdoovi ja voronka kihistu vahel: esimeses oli elementide algne sisaldus suurem, nende väljakanne hallidest erimitest on olnud intensiivne, teises olid sisaldused algselt väiksemad ning võib täheldada elementide kontsentreerumist hallidesse kivimitüüpidesse. Lontova kihistu merelistes savides on elementide suhted veelgi keerukamad, ühemõtteliselt selget väljakannet punaste kivimite ümberkujunemisel hallilaigulisteks ei ole siiski toimunud.

$\mathrm{Ka}$ hilisem götiitne ookristumine ei ole elemente oluliselt mobiliseerinud ega kontsentreerinud ühelgi uuritud stratigraafilisel tasemel - erandiks on olnud vaid vanaadiumi kuhjumine lontova kihistu ookristunud savides.

\section{BITYUKOVA, E. PIRRUS}

\section{DISTRIBUTION OF MICROELEMENTS IN COLOURED CLAY ROCKS OF THE NORTH-EAST BALTIC VENDIAN AND CAMBRIAN}

Data of the distribution of microelements in the Vendian and Cambrian clay rocks obtained by spectral analysis have been analyzed. It has been shown that there exists no common law of the element distribution for the primary red and secondary grey rocks - the relations between elements are different in different stratigraphical units. Essential differences between the Gdovian and Voronka Formations were formed under the conditions similar to the Vendian: in the former the primary content of elements was higher and the chemical subtration from the grey varieties more intensive; in the latter the content of elements was lower and they were concentrated in grey rocks. In the marine clays of the Lontova Formation relations between the elements are even more complicated, no essential subtration has been observed there during the colouring of the rock. The later goethitic ochridization did not mobilize or concentrate the elements - only vanadium in the Lontova Formation is an exception in this respect. 